\section{Meaning in Life in Patients With Progressive Supranuclear Palsy}

American Journal of Hospice \& Palliative Medicine ${ }^{\circledR}$ 20I4, Vol. 3I(5) 543-547

(C) The Author(s) 2013

Reprints and permission: sagepub.com/journalsPermissions.nav DOI: 10.1 I77/1049909। I34924I। ajhpm.sagepub.com

(9SAGE

\author{
Martin Johannes Fegg, PhD', Monika Kögler, MA', \\ Carina Abright, $M D^{2}$, Mira Hensler, $M D^{\prime}$, and Stefan Lorenzl, MD'
}

\begin{abstract}
This exploratory study investigated meaning in life (MiL) in patients with progressive supranuclear palsy (PSP). In the "Schedule for Meaning in Life Evaluation" (SMiLE), respondents list individual MiL areas before rating their current satisfaction and importance with them (index of weighting [loW], index of satisfaction [loS], and index of weighted satisfaction [loWS], range 0-100). A total of 38 patients with PSP completed the SMiLE (IoS: $68.6 \pm 25.6$, loW: $79.6 \pm 12.6$, and loWS: $69.2 \pm 26.1$ ). A representative sample of healthy participants $(n=977)$ scored significantly higher in the $\operatorname{loS}(82.8 \pm 14.7, P<.001)$, the loW $(85.6 \pm 12.3, P=.006)$, and the loWS $(83.3 \pm 14.8, P<.00 \mathrm{I})$. Compared to healthy individuals, patients with PSP were less likely to list health $(P=.00 \mathrm{I})$ and more likely to list partner $(P=.04)$, leisure $(P=.0 \mathrm{I})$, home/garden $(P=.0 \mathrm{I})$, and pleasure $(P=.02)$. Patients with PSP seem to focus on supportive relationships and leisure, while the decreasing health status is becoming less important to them.
\end{abstract}

\title{
Keywords
}

meaning in life, progressive supranuclear palsy, coping, response shift

\section{Background}

Progressive supranuclear palsy (PSP) is an incurable, neurological disease that is characterized by vertical ophthalmoparesis, early falls (tendency to topple backwards), akinetic-rigid features, prominent bulbar dysfunction, and frontosubcortical dementia. ${ }^{1-3}$ The loss of independent gait, the inability to stand unassisted, occurs in less than 3 years after the disease onset. ${ }^{4}$ With an average annual incidence of 1.2 per 100.000 and an age-adjusted prevalence of 6.4 per 100.000, PSP is as common as motor neuron disease or multiple system atrophy. ${ }^{5}$ Usually, the illness starts during the second life phase, between the age of 50 and 70 years. Men and women are almost equally affected. With a median survival of 5.8 years after the onset of symptoms, PSP is an incurable, progressive disease ${ }^{1}$; the negative outcomes of the vast majority of the studies make it difficult to set treatment standards. ${ }^{6}$

In the palliative care situation, existential questions arise when patients face the transitoriness of their lives. The search for meaning is one of the central coping mechanisms at the end of life. ${ }^{7}$ Meaning seems to be a safeguard against depression, hopelessness, and desire for hastened death among terminally ill patients. ${ }^{8}$ Therefore, the construct "meaning in life" (MiL) has stimulated the interest of clinicians and researchers in palliative care, and psychotherapeutic interventions focusing on meaning have been developed. ${ }^{9-11}$

A number of questionnaires have been created to capture MiL. However, for the most part they measure the intensity of meaning but tend to neglect the content of the reported meaning, which can be expected to vary from person to person and from situation to situation. ${ }^{12}$ The "Schedule for Meaning in Life Evaluation" (SMiLE) was specifically developed as an instrument for the assessment of individual MiL. This instrument has been successfully validated in palliative care patients. $^{13-16}$

\section{Objectives}

So far, only few studies exist describing health-related quality of life in patients with PSP. ${ }^{17-19}$ The aim of this exploratory study was to investigate the MiL in patients with PSP and compare the findings with data from a healthy, representative nationwide sample, where 13 categories of MiL had been summarized. ${ }^{20}$

More specifically, the study aimed (1) to evaluate and categorize individually important MiL areas in patients with PSP and (2) to examine the differences between patients with PSP

\footnotetext{
' Department of Palliative Medicine, Ludwig Maximilians University of Munich, Marchioninistr 15, Munich, Germany

${ }^{2}$ Department of Neurology, Ludwig Maximilians University of Munich, Marchioninistr 15, Munich, Germany

\section{Corresponding Author:}

Martin Johannes Fegg, PhD, Ludwig Maximilians University of Munich, Marchioninistr 15, Munich 81377, Germany.

Email: martin@fegg.de
} 
and healthy individuals with regard to the extent of MiL experienced as well as to the categories of areas important for MiL.

\section{Methods}

\section{Study Design and Participants}

The study had a cross-sectional design; patients with PSP treated at the Outpatient Clinic of the Department of Neurology at the Munich University Hospital, Germany, from April 2005 to November 2008 were eligible for the study.

Patients were tested whether they had definite or probable PSP according to the diagnostic criteria. ${ }^{21}$ All patients gave informed consent prior to study participation. The questionnaire was mailed to the patients. The study has been approved by the Research Ethics Committee of the Munich University Hospital.

\section{The Schedule for Meaning in Life Evaluation}

The SMiLE is an individualized measure of MiL; respondents are asked to list up to 7 areas important for their MiL before rating the current level of satisfaction with and the importance of each area. The level of satisfaction with each area is rated on a 7-point Likert-type scale, ranging from -3 "very unsatisfied" to +3 "very satisfied". The importance of each area is rated with an 8-point scale, ranging from 0 "unimportant" to 7 "extremely important".

The index of satisfaction (IoS) indicates the mean satisfaction or dissatisfaction with the individual MiL areas; the index of weighting (IoW) indicates the mean weighting of the MiL areas; in the total SMiLE index (index of weighted satisfaction [IoWS]), the ratings for importance and satisfaction are combined (all ranges 0-100, with higher scores reflecting higher MiL). Calculation of indices is reported elsewhere. ${ }^{13}$

\section{Statistical Analysis}

Student $t$ test was used to compare the number of MiL areas listed in each group. Linear models were performed to test for differences between the patients with PSP and the representative sample in the satisfaction and importance ratings as well as the global scores (IoS, IoW, and IoWS). Age and sex were entered into the model as confounding variables, because a nationwide study has shown that these variables significantly influence respondents' MiL. ${ }^{20}$

To identify differences in the likelihood of listing a specific MiL area, binary logistic regressions were performed. Age, sex, and the number of remaining areas named by each participant were entered into the model as potentially confounding variables.

For all the models, the unstandardized regression coefficient $(B)$ for the group variable, its standard deviation, and its respective $P$ value are presented. Additionally, for the linear models, the total explained variance $\left(R^{2}\right)$ is given. For the binary logistic regression analyses, the $\operatorname{Exp}(B)$ (ie, odds ratios) for the group variable along with its confidence intervals $(C I \operatorname{Exp}(B))$ is presented.
Differences were considered to be statistically significant at $P<.05$. Statistical tests were performed with the SPSS, version 15.0.1.

\section{Results}

\section{Participation in the Study}

A total of 70 patients were asked to participate, 38 patients returned a completed SMiLE (response rate, 54\%). Reasons for not participating were too poor physical condition $(n=20)$, refusal to participate in a study $(n=10)$, and significant cognitive impairment $(n=2)$.

\section{Participants' Characteristics}

Patients with PSP were $67.9 \pm 6.4$ years old, with $57.9 \%$ being female. With the very first PSP symptoms being reported $6.8 \pm 3.1$ years ago, the patients were in advanced stages of their disease (stage II or III). Compared to the healthy sample (median 40-49 years, $57.3 \%$ female), there was a significant difference in age $(P<.001)$ but not in gender $(P=.83)$. To complete the questionnaire, $11 \%$ needed no help, $28 \%$ needed assistance, and $61 \%$ were answered by relatives.

\section{Meaning in Life in Patients With PSP Compared to a Representative Sample}

Table 1 shows the descriptive statistics of the SMiLE indices as well as linear regression results, examining the differences between the patients with PSP and the representative sample. Healthy participants showed significantly higher IoS, IoW, and IoWS (SMiLE index) compared to patients with PSP.

\section{Categories of MiL}

Patients with PSP listed more areas representing their MiL $(4.4 \pm 1.8)$ compared to the representative sample $(3.8 \pm$ $1.4 ; t=-2.0 ; P=.05)$.

All listings were assigned to 13 categories derived from the representative survey. ${ }^{20}$ Table 2 presents percentages of participants in both the samples who listed MiL areas in the respective category along with means and standard deviations of the satisfaction and importance ratings. It also shows significant differences in the frequency of the listed MiL areas.

Health was listed less often by patients with PSP; the chance that this area is relevant for meaning is 12.3 times lower compared to the representative sample. However, leisure, partner, home/garden, and pleasure were listed more often by patients with PSP.

Satisfaction With MiL Areas. Compared to healthy Germans, patients with PSP were significantly less satisfied in health, leisure, friends, partner, finances, and altruism (Table 3). 
Table I. Linear Models for the Main Outcome Scores of the SMiLE (loW, loS, and loWS). ${ }^{\text {a }}$

\begin{tabular}{|c|c|c|c|c|c|c|c|c|}
\hline \multirow[b]{2}{*}{ SMiLE indices } & \multirow{2}{*}{$\begin{array}{l}\text { Patients with } \\
\text { PSP } M \pm S D\end{array}$} & \multirow{2}{*}{$\begin{array}{l}\text { Representative } \\
\text { sample } M \pm S D\end{array}$} & \multirow[b]{2}{*}{ Total $R^{2}$} & \multirow[b]{2}{*}{$B$} & \multirow[b]{2}{*}{$\mathrm{SE}(B)$} & \multicolumn{2}{|c|}{$C l \operatorname{Exp}(B)$} & \multirow[b]{2}{*}{$P$} \\
\hline & & & & & & Low & High & \\
\hline IoS & $68.6 \pm 25.5$ & $82.8 \pm 14.7$ & .05 & 16.9 & 2.7 & I I.6 & 22.1 & $<.001$ \\
\hline loW & $79.6 \pm 12.6$ & $85.6 \pm 12.3$ & .03 & 6.0 & 2.2 & 1.7 & 10.2 & .006 \\
\hline loWS & $69.2 \pm 26.1$ & $83.3 \pm 14.8$ & .04 & 16.4 & 2.7 & II.I & 21.7 & $<.001$ \\
\hline
\end{tabular}

Abbreviations: $B$, unstandardized regression coefficient; $\mathrm{Cl}$, confidence interval; loW, index of weighting; loS, index of satisfaction; loWS, index of weighted satisfaction; M, mean; PSP, progressive supranuclear palsy; SMiLE, Schedule for Meaning in Life Evaluation; SD, standard deviation; SE(B), standard deviation of $B$.

${ }^{a}$ Results of 3 linear models with loW, loS, and loWS as dependent variables. Factors include group membership (patients with PSP vs representative sample), age, and sex.

Table 2. Areas of MiL. ${ }^{\mathrm{a}}$

\begin{tabular}{|c|c|c|c|c|c|c|c|c|c|c|c|}
\hline & \multirow{2}{*}{\multicolumn{3}{|c|}{ Patients with PSP }} & \multirow{2}{*}{\multicolumn{3}{|c|}{ Representative sample }} & \multirow[b]{3}{*}{$\operatorname{Exp}(B)$} & \multicolumn{4}{|c|}{ Binary logistic regression } \\
\hline & & & & & & & & \multicolumn{2}{|c|}{$C I \operatorname{Exp}(B)$} & \multirow[b]{2}{*}{$B \pm S D$} & \multirow[b]{2}{*}{$P$} \\
\hline & $\%$ & $S ; M \pm S D$ & $W ; M \pm S D$ & $\%$ & $S ; M \pm S D$ & $W ; M \pm S D$ & & Low & High & & \\
\hline Family & 78.9 & $2.3 \pm .9$ & $6.3 \pm 1.0$ & 83.3 & $2.3 \pm 1.0$ & $6.6 \pm 1.0$ & 0.9 & 0.4 & 2.2 & $-.1 \pm .5$ & .84 \\
\hline Leisure & 60.5 & $.5 \pm 2.4$ & $5.2 \pm 1.5$ & 36.2 & $1.7 \pm 1.2$ & $4.8 \pm 1.5$ & 0.4 & 0.2 & 0.8 & $-.9 \pm .4$ & .01 \\
\hline Friends & 39.5 & $1.5 \pm .1 .3$ & $4.7 \pm 1.8$ & 40.4 & $2.2 \pm 0.9$ & $6.0 \pm 1.1$ & 0.5 & 0.3 & I.I & $-.7 \pm .4$ & .07 \\
\hline Partner & 28.9 & $1.8 \pm 1.9$ & $6.7 \pm .7$ & 26.9 & $2.3 \pm 1.1$ & $6.6 \pm .9$ & 0.4 & 0.2 & 1.0 & $-.8 \pm .4$ & .04 \\
\hline Home/garden & 23.7 & $1.7 \pm 2.1$ & $6.1 \pm .9$ & 7.2 & $2.0 \pm 1.2$ & $4.9 \pm 1.5$ & 0.3 & 0.1 & 0.8 & $-1.2 \pm .5$ & .01 \\
\hline Nature/animals & 15.8 & $1.7 \pm 1.2$ & $4.7 \pm 1.4$ & 8.3 & $2.4 \pm 0.9$ & $5.8 \pm 1.3$ & 0.7 & 0.3 & 2.0 & $-.3 \pm .5$ & .55 \\
\hline Work & 15.8 & $1.2 \pm 2.3$ & $3.6 \pm 2.6$ & 56.2 & $1.4 \pm 1.6$ & $5.4 \pm 1.4$ & 1.2 & 0.4 & 3.2 & $.2 \pm .5$ & .76 \\
\hline Pleasure & 15.8 & $.8 \pm 2.4$ & $6.3 \pm .8$ & 3.8 & $1.8 \pm 1.4$ & $5.7 \pm 1.4$ & 0.3 & 0.1 & 0.8 & $-1.3 \pm .6$ & .02 \\
\hline Health & 5.3 & $-2.5 \pm .7$ & $4.5 \pm 2.1$ & 30.0 & $1.8 \pm 1.5$ & $6.7 \pm .8$ & 12.3 & 2.8 & 53.4 & $2.5 \pm .8$ & .001 \\
\hline Altruism & 5.3 & $0 \pm 4.2$ & $4.5 \pm .7$ & 3.8 & $2.0 \pm 1.0$ & $5.2 \pm 1.2$ & 1.6 & 0.4 & 7.2 & $.5 \pm .8$ & .56 \\
\hline Spirituality & 5.3 & $2.5 \pm .7$ & $4.7 \pm 1.5$ & 7.2 & $2.4 \pm 0.8$ & $6.1 \pm 1.4$ & 3.6 & 0.8 & 15.6 & $1.3 \pm .8$ & .09 \\
\hline Finances & 2.6 & $-3 \pm 0$ & $\overline{3}$ & 13.4 & $.9 \pm 1.8$ & $5.0 \pm 1.5$ & 4.3 & 0.6 & 32.6 & $1.5 \pm 1.0$ & .16 \\
\hline Well-being & - & - & - & 4.1 & $1.7 \pm 1.3$ & $6.0 \pm 1.3$ & - & - & - & - & - \\
\hline
\end{tabular}

Abbreviations: $B$, unstandardized regression coefficient; $\mathrm{Cl}$, confidence interval; $\mathrm{M}$, mean; MiL, meaning in life; PSP, progressive supranuclear palsy; S, satisfaction; $\mathrm{SD}$, standard deviation; $\mathrm{W}$, importance ratings.

${ }^{a}$ Percentages of respondents listing each category, $M$ and SD of the $S$ (range -3 to +3 ) and $W$ (range 0-7). Last 5 columns show the results of the binary logistic regression model predicting listing of specific MiL areas from group membership (patients with PSP vs representative sample) controlled for age, sex, and number of remaining $\mathrm{MiL}$ areas.

Note. Bold values signify $P \leq 0.05$.

Importance of MiL Areas. Compared to healthy Germans, patients with PSP rated work and health significantly lower (Table 3).

Meaning in Life and Time Since the Onset of Disease. Time since the onset of very first symptoms of the disease observed by the patient was a significant predictor for MiL satisfaction (IoS and IoWS; Table 4). The longer the time interval, the lower were the overall satisfaction and weighted satisfaction scores. No significant differences were found in the linear models for the likelihood of listing MiL areas, satisfaction with, and importance of MiL areas.

\section{Discussion}

This study evaluated MiL in patients with advanced PSP and compared the findings with data from a nationwide survey in healthy individuals. ${ }^{20}$ The categories mentioned most often by the patients were family, leisure, friends, and partner. Compared to healthy individuals, patients with PSP were significantly less likely to list health and more likely to list leisure, partner, home/ garden, and pleasure.

This result could be explained by "response shift" in the coping process following the diagnosis of PSP. Response shift is defined as a change in internal standards, values, or conceptualizations, which mediates the accommodation of patients with a life-threatening or chronic disease to their illness. ${ }^{22}$ With the decreasing health status, patients with PSP shift their focus away from health and toward close relationships, leisure, pleasure, and home/garden as meaning providing areas. This has already been observed in patients with amyotrophic lateral sclerosis ${ }^{16}$ and palliative care patients. ${ }^{15}$

With regard to the overall indices, patients with PSP scored lower in all SMiLE scores (IoS, IoW, and IoWS) compared to the representative sample. However, their overall MiL was still quite high ( $>68$, range 0-100). Regarding the importance ratings, patients with PSP scored significantly lower only in work and health which can also be interpreted in terms of response shift. Examining the satisfaction ratings of specific areas, it is noteworthy that satisfaction scores of patients with PSP are fairly high (and not significantly 
Table 3. Linear Models for Satisfaction and Importance Ratings. ${ }^{a}$

\begin{tabular}{|c|c|c|c|c|c|c|c|c|}
\hline \multirow[b]{2}{*}{ MiL category } & \multicolumn{4}{|c|}{ Satisfaction } & \multicolumn{4}{|c|}{ Importance } \\
\hline & Total $R^{2}$ & B & $\mathrm{SE}(B)$ & $P$ & Total $R^{2}$ & B & $\mathrm{SE}(B)$ & $P$ \\
\hline Family & .01 & .26 & .19 & .18 & .02 & .31 & .20 & .13 \\
\hline Leisure & .06 & 1.43 & .32 & $<.001$ & .03 & -.49 & .36 & .17 \\
\hline Friends & .04 & .77 & .28 & .006 & .12 & .87 & .33 & .009 \\
\hline Partner & .04 & .79 & .39 & .05 & .02 & .01 & .29 & .99 \\
\hline Home/garden & .08 & .73 & .50 & .15 & .21 & -.70 & .57 & .23 \\
\hline Nature/animals & .20 & .70 & .40 & .09 & .30 & .90 & .50 & .08 \\
\hline Work & .01 & .51 & .69 & .47 & .03 & 1.84 & .64 & .004 \\
\hline Pleasure & .19 & .98 & .85 & .26 & .25 & -1.22 & .67 & .09 \\
\hline Health & .08 & 3.96 & 1.06 & $<.001$ & .11 & 2.32 & .60 & $<.001$ \\
\hline Altruism & .23 & 2.48 & .93 & .01 & .09 & .75 & .94 & .43 \\
\hline Spirituality & .09 & -.01 & .60 & .99 & .11 & 1.54 & .84 & .07 \\
\hline Finances & .14 & 4.79 & 1.90 & .01 & .09 & .99 & 1.59 & .54 \\
\hline
\end{tabular}

Abbreviations: $B$, unstandardized regression coefficient; MiL, meaning in life; PSP, progressive supranuclear palsy; $\mathrm{SE}(B)$, standard deviation of $B$.

${ }^{a}$ Results of linear models with satisfaction and importance ratings as dependent variables and group membership (patients with PSP vs representative sample), age, and sex as factors $(\mathrm{n}=1015)$.

Note. Bold values signify $P \leq 0.05$.

Table 4. Linear Models of the Impact of Time Since Onset of the Disease in Patients With PSP. ${ }^{\text {a }}$

\begin{tabular}{lcccccc}
\hline SMiLE indices & Total $R^{2}$ & $\begin{array}{c}B \text { (time since } \\
\text { onset of disease) }\end{array}$ & $\mathrm{SE}(B)$ & $\begin{array}{c}\mathrm{Cl} \operatorname{Exp}(B) \\
\text { Low }\end{array}$ & $\begin{array}{c}\mathrm{Cl} \operatorname{Exp}(B) \\
\text { High }\end{array}$ & $P$ \\
\hline loS & .3 & -4.6 & 1.4 & $-\mathbf{7 . 4}$ & $-\mathbf{1 . 7}$ & $\mathbf{0 0 2}$ \\
loW & .02 & -.4 & .8 & -2.0 & 1.3 & .65 \\
loWS & .3 & $-\mathbf{4 . 8}$ & 1.4 & $-\mathbf{7 . 6}$ & -1.9 & .002 \\
\hline
\end{tabular}

Abbreviations: $B$, unstandardized regression coefficient; $\mathrm{Cl}$, confidence interval; loW, index of weighting; loS, index of satisfaction; loWS, index of weighted satisfaction; PSP, progressive supranuclear palsy; $\mathrm{SE}(B)$, standard deviation of $B$; SMiLE, Schedule for Meaning in Life Evaluation.

${ }^{a}$ Results of 3 linear models with loW, loS, and loWS as dependent variables, time since onset of disease as covariate and age and sex as factors.

Note. Bold values signify $P \leq 0.05$.

lower than their healthy counterparts) in a number of domains (family, home/garden, nature/animals, work, spirituality, and pleasure). On the other hand, they score significantly lower in leisure, friends, partner, health, finances, and altruism. In health and finances, score of patients with PSP is negative. Due to the loss of physical autonomy, patients with PSP have to focus their family and home setting. Motor dysfunction, cognitive impairment, and dementia may lead to dependence from next kins and may also lead to decreased satisfaction in some MiL areas.

In conclusion, the SMiLE seems to reflect different components of MiL; the areas listed by a patient with PSP provide the framework of where an individual finds meaning (also reflected in the importance ratings). This seems to be an aspect of MiL that is mostly sustained during the illness. Where patients with PSP encounter some problems, however, is the fulfillment of MiL. This aspect, reflected in the diminished satisfaction ratings in certain domains, is where patients experience loss of meaning.

This study has several limitations; most patients either needed assistance to complete the questionnaire or the SMiLE has been answered by their relatives. This might lead to biases in the interpretation of the data. However, the primary caregiver is one of the most valid sources of patients' needs, especially in advanced stages of the disease. ${ }^{23}$ Proxy-based ratings of the SMiLE are possible in general and might be established under certain circumstances. ${ }^{13}$

This is the first exploratory study on MiL of patients with advanced PSP; future research should investigate earlier stages of the disease to compare with these findings. Standardized disease-related parameters and their relation to MiL should be included in the study protocols (eg, the Progressive Supranuclear Palsy Rating Scale [PSPRS $]^{24}$ ). Furthermore, it will be necessary to assess the burden of the caregivers, since some studies have pointed out the distress of family members in patients with PSP ${ }^{25}$ palliative care patients, and patients with cancer. ${ }^{26,27}$

Therefore, it will be necessary to develop psychosocial interventions for both patients with PSP and their relatives as a "unit of care." ${ }^{28}$ Impairments in MiL assessed with the SMiLE might provide a basis for an individualized support to maintain and enhance MiL in patients with PSP and their family caregivers.

\section{Declaration of Conflicting Interests}

The authors declared no potential conflicts of interest with respect to the research, authorship, and/or publication of this article. 


\section{Funding}

The authors received no financial support for the research, authorship, and/or publication of this article.

\section{References}

1. Bensimon G, Ludolph A, Agid Y, Vidailhet M, Payan C, Leigh P. Riluzole treatment, survival and diagnostic criteria in Parkinson plus disorders: the NNIPPS Study. Brain. 2009;132(1):156-171.

2. Ludolph A, Kassubek J, Landwehrmeyer B, et al. Tauopathies with parkinsonism: clinical spectrum, neuropathologic basis, biological markers, and treatment options. Eur J Neurol. 2009; 16(3):297-309.

3. Litvan I, Baker M, Hutton M. Tau genotype: no effect on onset, symptom severity, or survival in progressive supranuclear palsy. Neurology. 2001;57(1):138-140.

4. Goetz C, Leurgans S, Lang A, Litvan I. Progression of gait, speech and swallowing deficits in progressive supranuclear palsy. Neurology. 2003;60(6):917-922.

5. Schrag A, Ben-Shlomo Y, Quinn N. Prevalence of progressive supranuclear palsy and multiple system atrophy: a cross-sectional study. Lancet. 1999;354(9192):1771-1775.

6. Litvan I. Atypical parkinsonian disorders. Movement Disord. 2004;10(3):42-64.

7. Folkman S, Greer S. Promoting psychological well-being in the face of serious illness: when theory, research and practice inform each other. Psychooncology. 2000;9(1):11-19.

8. Breitbart W, Rosenfeld B, Pessin H, et al. Depression, hopelessness, and desire for hastened death in terminally ill cancer patients. JAMA. 2000;284(22):2907-2911.

9. Breitbart W, Rosenfeld B, Gibson C, et al. Meaning-centered group psychotherapy for patients with advanced cancer: a pilot randomized controlled trial. Psychooncology. 2010;19(1):21-28.

10. Lee V, Cohen R, Edgar L, Laizner A, Gagnon A. Meaningmaking intervention during breast or colorectal cancer treatment improves self-esteem, optimism, and self-efficacy. Soc Sci Med. 2006;62(12):3133-3145.

11. Chochinov H, Kristjanson L, Breitbart W, et al. Effect of dignity therapy on distress and end-of-life experience in terminally ill patients: a randomised controlled trial. Lancet Oncol. 2011; 12(8):753-762.

12. O'Boyle C. Making subjectivity scientific. Lancet. 1995;345:602.

13. Fegg M, Kramer M, L'hoste S, Borasio G. The Schedule for Meaning in Life Evaluation (SMiLE): validation of a new instrument for meaning-in-life research. J Pain Symptom Manage. 2008;35(4):356-363.
14. Stiefel F, Krenz S, Zdrojewski K, et al. Meaning in life assessed with the "Schedule for Meaning in Life Evaluation" (SMiLE): a comparison between a cancer patient and student sample. Support Care Cancer. 2008;16(10):1151-1155.

15. Fegg M, Brandstätter M, Kramer M, Kögler M, HaarmannDoetkotte S, Borasio G. Meaning in life in palliative care patients. J Pain Symptom Manage. 2010;40(4):502-509.

16. Fegg M, Kögler M, Brandstätter M, et al. Meaning in life in patients with amyotrophic lateral sclerosis. Amyotroph Lateral Scler. 2010;11(5):469-474.

17. Schrag A, Selai C, Davis J, Lees A, Jahanshahi M, Quinn N. Health-related quality of life in patients with progressive supranuclear palsy. Mov Disord. 2003;18(12):1464-1469.

18. Schrag A, Selai C, Quinn N, Hobart J. Measuring health-related quality of life in patients with progressive supranuclear palsy. Neurocase. 2005;11(4):246-249.

19. Schrag A, Selai C, Quinn N, Lees A, et al. Measuring quality of life in PSP: the PSP-QoL. Neurology. 2006;67(1):39-44.

20. Fegg M, Kramer M, Bausewein C, Borasio G. Meaning in life in the Federal Republic of Germany: results of a representative survey with the Schedule for Meaning in Life Evaluation (SMiLE). Health Qual Life Out. 2007;5:59.

21. Litvan I, Agid Y, Calne D, et al. Clinical research criteria for the diagnosis of progressive supranuclear palsy (Steele-RichardsonOlszewski syndrome): report of the NINDS-SPSP international workshop. Neurology. 1996;47(1):1-9.

22. Sprangers M, Schwartz C. Integrating response shift into healthrelated quality of life research: a theoretical model. Soc Sci Med. 1999;48(11):1507-1515.

23. Milne D, Mulder L, Beelen H, Schofield P, Kempen G, Aranda S. Patients' self-report and family caregivers' perception of quality of life in patients with advanced cancer: how do they compare? Eur J Cancer Care (Engl). 2006;15(2):125-132.

24. Golbe L, Ohman-Strickland P. A clinical rating scale for progressive supranuclear palsy. Brain. 2007;130(pt 6):1552-1565.

25. Uttl B, Santacruz P, Litvan I, Grafman J. Caregiving in progressive supranuclear palsy. Neurology. 1998;51(5):1303-1309.

26. Pitceathly C, Maguire P. The psychological impact of cancer on patient's partners and other key relatives: a review. Eur J Cancer Care. 2003;39(11):1517-1524.

27. Hodges L, Humphris G, Macfarlane G. A meta-analytic investigation of the relationship between the psychological distress of cancer patients and their carers. Soc Sci Med. 2005;60(1):1-12.

28. Schulz R, Cook T, Beach S, et al. Magnitude and causes of bias among family caregivers rating Alzheimer disease patients. $\mathrm{Am}$ J Geriatr Psychiatry. 2013;21(1):14-25. 